\title{
XVII. Experiments on platina
}

\section{Richard Phillips F.R.S.L. \& E.}

To cite this article: Richard Phillips F.R.S.L. \& E. (1833) XVII. Experiments on platina, Philosophical Magazine Series 3, 2:8, 94-96, DOI: 10.1080/14786443308647980

To link to this article: http://dx.doi.org/10.1080/14786443308647980

曲 Published online: 01 Jun 2009.

Submit your article to this journal

Џ Article views: 3

Q View related articles $\asymp$ 
to be exactly as indicated by the undulatory theory: if the results were not widely different from this, he would undoubtedly refer the difference to error of experiment. We see that the experiment with the prism draws a clear line of distinction; but from what I have observed, I believe the velocity will not eventually be found extensively different from that according to the said theory. The slightest difference is, however, of fatal consequence; for the ratio ought, according to common consent, todepend rigorously on the refractive index, which is one of the fundamental principles of the theory.

XVII. Experiments on Platina. By Richard Phillips, F.R.S. L.\& E. \&c.

THE third volume of the Quarterly Journal of Science contains a paper, by Mr. J. T. Cooper, On some Combinations of Platinum. In this communication the author states, that when a neutral solution of tartrate of soda is heated with one of muriate of platina, a blackish powder is precipitated: this substance after being washed, was dried on a sandbath at $300^{\circ}$, in order to free it from uncombined water; it lost afterwards 2.8 per cent. by exposure to a red heat; and as nothing could be procured from the black powder but platina and water, Mr. Cooper considers it to be a hydrate of the metal, composed of $44.328=2$ atoms of platina $+1 \cdot 125$ $=1$ atom of water: these proportions agree tolerably well with the results of the experiment.

It is singular that Mr. Cooper does not particularly advert to the interesting fact which he announces; for this is, I believe, the first instance on record of the combination of water with a metal, not previously converted into an oxide; and it is almost as remarkable, that of the numerous authors whom I have consulted on the subject, no one mentions this compound.

Although, with some particular views, I have repeatedly formed this black powder, it is only lately that I have investigated its properties. Having dissolved some platina and precipitated it in the manner described, I duly washed the powder and dried it at $212^{\circ}$; after this I gradually heated it to redness, and found that it diminished $1 \cdot 4.1$ per cent. in weight. This experiment, slightly varied, was repeated with a difference of only 0.14 per cent. in the weight lost. It will be observed that although Mr. Cooper dried the precipitate at $300^{\circ}$, while I subjected it only to $212^{\circ}$ before heating it to redness, yet I found the diminution of weight, caused by the subsequent and higher temperature, to be but little more than half of that which occurred in his experiment. 
Supposing, therefore, the black precipitate to be a hydrate of platina, it would appear by my experiments to be a compound of about four atoms of the metal and one atom of water. Now the existence of a hydrate so constituted is not only of itself extremely improbable, but is rendered still more unlikely by the supposition that a metal without previous oxidizement should form a hydrate at all; for it is quite as contrary to experience that a metal and water should combine, as that a metal and an acid should unite, without the intervention of oxygen.

I an therefore disposed to consider the 1.41 per cent. of water which remains with the black powder, after being heated to $212^{\circ}$, as in a state of mixture, and not of combination. There are other circumstances which strengthen this conclusion: If the black powder be strongly pressed or rubbed in a glass mortar, the metallic appearance of platina is as perfect before as after the application of a red heat; and I conceive this could scarcely occur if it were chemically combined with water. That the platina is in the metallic state in the black powder, is proved by its total insolubility in nitric or muriatic acid, even when first precipitated, and before it is dried. Another circumstance which induces me to believe that it is not a hydrate, is its answering most perfectly the purpose of spongy platina in firing a jet of hydrogen gas, and detonating a mixture of oxygen and hydrogen gases; indeed it appears to me to be an excellent preparation for these purposes, and it is procured with very great facility.

It is probable that some other metals whose affinity for oxygen is weak, may also be precipitated in the metallic state by the tartrates; and $I$ have found this to be the case with gold: when tartrate of soda is added to the muriatic solution of that metal, no effect is produced until heat is applied, and then the precipitation of metallic gold is as rapid, and quite as remarkable as that of platina.

Tartrate of soda being a salt not usually kept, I have sometimes employed tartrate of potash: when the solutions are cold, the well-known double salt of potash and platina is precipitated; but on the application of heat the black powder is very quickly formed; the same effect is produced by tartrate of lime and tartrate of ammonia; but neither tartaric acid nor bitartrate of potash determine precipitation until an alkali is added.

It appears to me that muriate of platina may be very advantageously employed as a test of the presence of tartaric acid, provided it be first saturated or supersaturated with an alkali.

During the formation of the black powder, there is an evident evolution of some gas: suspecting it to be carbonic acid 
I passed it into lime-water and obtained a plentiful precipitate; it is probable therefore that the hydrogen of the tartaric acid combines with the oxygen of the platina, and thus reduces it to the metallic state; whilst the carbon and oxygen of the tartaric acid form carbonic acid gas.

I am at present engaged in some researches upon the oxideof platina, thrown down by the action of protonitrate of mercury.

XVIII. Notice of the Arrival of Thenty-six of the Summer Birds of Passage in the Neighbourhood of Carlisle, during the Spring of 1832, together with some of the scarcer Species that have been obtained in the same Vicinity from the 10 th of November 1831, to the 10th of November 1832; with Observations, \&c. By A Corresponden?**

\begin{tabular}{|c|c|c|c|c|c|}
\hline No. & English Specific Names. & $\begin{array}{l}\text { Latin Generic and } \\
\text { Specific Names. }\end{array}$ & \multicolumn{2}{|c|}{$\begin{array}{l}\text { When first } \\
\text { olsserved. }\end{array}$} & No. \\
\hline 1 & Quail & Coturnix vulgaris.. & May & 12 & 6 \\
\hline 2 & Swallow., & Hirundo rustica ... & April & 12 & 35 \\
\hline $\mathbf{3}$ & House Martin .. & — urbica .... & & 16 & 36 \\
\hline 4 & Sand Martin.... & -_ riparia ... & Marc & 29 & 36 \\
\hline 5 & wift .. & Cypselus $\Lambda$ pus..... & April & 27 & 37 \\
\hline 6 & Goatsucker... & Caprimulgus europæus .. & May & 10 & 38 \\
\hline 7 & Pied Flycatcher. & Muscicapa atricapilla ... & April & 22 & 41 \\
\hline 8 & Spotted Flycatcher & - Grisola...... & May & 7 & 42 \\
\hline 9 & Ring Ouzel ...... & Turdus torquatus........ & April & 1 & 49 \\
\hline 10 & Wheatear..... & Saxicola OEnanthe.. & & 1 & 53 \\
\hline 11 & Whinchat... & - Rubetra ... & & 16 & 54 \\
\hline 12 & Redistar & Sylvia Phœnicurus & & 18 & 57 \\
\hline 13 & Grasshopper War & Curruca Locustella. & Marel & 31 & 58 \\
\hline 14 & Sedge Warbler.. & — salicaria... & May & $\mathbf{3}$ & 59 \\
\hline 15 & Greater Pettychaps ... & ___ hortensis ....... & & 6 & 62 \\
\hline 16 & Wood Wren........... & - - sibilatrix ....... & April & 24 & 63 \\
\hline 17 & Blackcap .......... & $\begin{array}{l}\text { A tricapilla } . . . \\
\text { Svlvia........ }\end{array}$ & & $\begin{array}{r}27 \\
3\end{array}$ & 64 \\
\hline 19 & Yellow Wren & Regulus Troc & April & 12 & 70 \\
\hline 20 & Yellow Wagtai & Motacilla flava..... & & 18 & 75 \\
\hline 21 & Field Lark or Titling... & Anthus trivialis ....... & - & 19 & 78 \\
\hline 22 & Cuckoo ....... & Cuculus canorus ... & - & 16 & 121 \\
\hline 23 & Wryneck .... & Yunx Torquilla.... & & 22 & 125 \\
\hline 24 & Corncrake or Land & Ortygometra Crex ...... & & 14 & 129 \\
\hline 25 & Dottrel........ & Charadrius Morinellus... & May & 7 & 164 \\
\hline 26 & Common Tern......... & Sterna Hirundo....... & & 18 & 235 \\
\hline
\end{tabular}

[Note. -The figures contained in the column on the right in the above Table, as well as those affixed to the species not included in it, refer to the numbers in Fleming's History of British Animals, which we have inserted, in order that the reader who wishes to have a description or to see the various synonyms of any of the birds here alluded to, may find the species at once, should he possess that highly useful and very excellent work.]

* Communicated by the Author. 